\title{
An observational study of clinical inertia among patients with type 2 diabetes mellitus in a tertiary care hospital
}

Piranee Kaewbut ${ }^{1,2}$, Natapong Kosachunhanun ${ }^{3}$, Arintaya Phrommintikul ${ }^{3}$, Dujrudee Chinwong ${ }^{4}$, John Hall 5 , Surarong Chinwong ${ }^{4}$

\author{
1PhD's Degree Program in Pharmacy, Faculty of Pharmacy, Chiang Mai University, \\ Chiang Mai, Thailand \\ ${ }^{2}$ Division of Pharmaceutical Care, School of Pharmaceutical Sciences, \\ University of Phayao, Phayao, Thailand \\ ${ }^{3}$ Department of Internal Medicine, Faculty of Medicine, Chiang Mai University, \\ Chiang Mai, Thailand \\ ${ }^{4}$ Department of Pharmaceutical Care, Faculty of Pharmacy, Chiang Mai University, \\ Chiang Mai, Thailand \\ ${ }^{5}$ School of Public Health and Community Medicine, University of New South Wales, \\ Sydney, Australia
}

Submitted: 29 May 2020

Accepted: 19 July 2020

Arch Med Sci

DOI: https://doi.org/10.5114/aoms.2020.98196

Copyright (c) 2020 Termedia \& Banach

\section{Abstract}

Introduction: Clinical inertia is a lack of treatment intensification despite a failure to achieve appropriate targets using a current management strategy. Research focusing on the clinical inertia in type 2 diabetes mellitus (T2DM) remains scant. This study aimed to investigate factors associated with clinical inertia among patients with T2DM.

Material and methods: This observational study was conducted in a tertiary teaching hospital using medical records. T2DM patients attending the outpatient clinic between 1 January 2017 and 31 December 2017 were included. Failure to intensify the diabetes treatment of the participants was assessed. For this study, clinical inertia was defined as any T2DM patient event with an glycated haemoglobin $\left(\mathrm{HbA}_{1 \mathrm{c}}\right)$ of $\geq 7.00 \%$ with no treatment intensification at the index date, or in a subsequent prescription written within the study time limits. Logistic regression analysis was used to determine associated factors.

Results: Of 5756 T2DM outpatients, 994 patients were enrolled in this study, with $26.2 \%$ of patients presenting clinical inertia. This study found that factors associated with lower clinical inertia were the use of insulin, $\mathrm{HbA}_{1 c}$ level at the index date, lower number of antidiabetic drugs used, and treatment by specialists (all $p$-value $<0.05$ ).

Conclusions: Clinical inertia is a problem of T2DM treatment. Strategies should be developed to decrease this problem.

Key words: clinical inertia, type 2 diabetes mellitus, tertiary care.

\section{Introduction}

Clinical inertia is a common problem with asymptomatic chronic disease management [1] and is defined as the failure to achieve appropriate targets because of delayed time to achieve treatment intensifica-
Corresponding author: Assoc. Prof. Surarong

Chinwong

Department of Pharmaceutical Care Faculty of Pharmacy Chiang Mai University Thailand

E-mail: surarong@gmail.com 
tion [2-4]. Three processes define clinical inertia in an operational sense. First, the clinical target must be selected. Second, the disease treatment must be defined and must be measurable. Finally, the time to evaluate treatment intensification must be determined $[1,5]$. Therefore, assessing clinical inertia in each chronic disease study differs. Type 2 diabetes mellitus (T2DM) is a major health problem worldwide [6], and drug therapies are not optimal [7]. Universal standard measurement to quantify clinical inertia is still lacking [8]. One study in the US revealed that $72.8 \%$ of patients with T2DM experienced clinical inertia [9]. In Thailand, Ostaphan et al. found that $68.4 \%$ of patients with T2DM had experienced clinical inertia [10]. Furthermore, Pholdee et al. reported that 5903 (38.8\%) patients had clinical inertia [11]. Clinical inertia can lead to cardiovascular complications and progress to diabetic retinopathy [10, 12]. Research focusing on clinical inertia in T2DM is well documented in developed countries [13, 14]. However, corresponding data are needed in developing countries [14].

A study by Osataphan et al. defined clinical inertia as a state in which patients with T2DM presenting an glycated haemoglobin $\left(\mathrm{HbA}_{1 \mathrm{c}}\right)$ level $\geq 9 \%$ did not receive treatment intensification with insulin initiation within three months [10]. This study evaluated clinical inertia based on injectable insulin only and also considered the results within a certain timeframe. A study by Pholdee et al. selected newly diagnosed T2DM patients [11] while clinical inertia can occur throughout [15]. Our study examined clinical inertia using new criteria: using both injectable and oral antidiabetic drugs (OADs) instead of a sole injectable or OADs alone, and evaluating clinical inertia at the index date or in a subsequent prescription written within the study time limits. In an attempt to describe the extent and factors associated with clinical inertia, this study examined the patterns of patients with T2DM treatment in a tertiary care hospital in Thailand.

\section{Material and methods}

\section{Study design}

An observational study was undertaken on patients with T2DM using existing data obtained from medical records and the electronic hospital database of the Maharaj Nakorn Chiang Mai Hospital in northern Thailand.

The study was approved by the Ethics Committee Board at the Faculty of Medicine, Chiang Mai University, Thailand.

\section{Database}

The Maharaj Nakorn Chiang Mai Hospital is a university hospital affiliated with Chiang Mai Uni- versity. This large tertiary care public hospital contains 1400 beds serving the needs of residents of Chiang Mai, Thailand (an approximate population of $1,800,000$ ), as well as patients referred from hospitals from nearby provinces in northern Thailand. It services an average of 1,300,000 outpatients and 46,000 inpatients yearly. All patient data were obtained from an electronic medical database (EMD). Data were entered in the EMD at the study hospital by trained nurses. The EMD comprised patient demographics, medications prescribed at any outpatient visits, laboratory data, follow-up appointment, and types of prescribers classified as general practitioners, residents, or specialists [16]. Then, all data were reviewed and recorded on a case record form (CRF) for data analysis.

\section{Study patients}

All T2DM patients attending the outpatient clinic at Maharaj Nakorn Chiang Mai Hospital between 1 January 2017 and 31 December 2017 were included. If patients were not followed up in this centre, be it at another centre or not at all, we excluded those patients from the study. Patients are advised to test for $\mathrm{HbA}_{1 c}$ once a year. In general, the doctor makes the appointment every three months unless the patient has high blood sugar at the time of the appointment. If they do, the next appointment can be earlier. Inclusion criteria: (1) a previous diagnosis of T2DM aged 40 to 65 years, (2) presenting an $\mathrm{HbA}_{1 \mathrm{c}}$ level $\geq 7.00 \%$ and (3) receiving at least $1 \mathrm{OAD}$. Exclusion criteria: (1) having a history of symptomatic hypoglycaemia, (2) pregnancy and lactation, (3) end-of-life care, (4) using insulin only, (5) multiple comorbidities, and (6) history of poor lifestyle modifications or adherence.

The comorbidity was evaluated using the Charlson Comorbidity Index $(\mathrm{Cl})$. The $\mathrm{CCl}$ predicts the 10-year survival of a patient who may have a range of comorbid conditions. Each condition is assigned a score of $1,2,3$, or 6 depending on the level of risk [17]. If participants had a CCI score of at least 3, they were classified as multiple comorbidities. Poor lifestyle modifications or adherence was identified when a patient was recorded on the medical card by the health care provider as having poor lifestyle modifications or nonadherence to treatment or missing their appointment.

\section{Definition of terms}

The index date was defined as the date of the first $\mathrm{HbA}_{1 \mathrm{c}}$ laboratory test above the target level $\left(\mathrm{HbA}_{1 \mathrm{c}} \geq 7.00 \%\right)$ during the study period from 1 January to 31 December 2017.

Clinical inertia was identified when an $\mathrm{HbA}_{1 c}$ level was found at $\geq 7.00 \%$, at the index date, 
followed by no treatment intensification from the index date and the subsequent prescription.

No clinical inertia was identified using two methods. First, patients had an $\mathrm{HbA}_{1 \mathrm{c}}$ level $\geq 7.00 \%$ at the index date and received treatment intensification at the index date or at a subsequent prescription. Second, patients did not receive treatment intensification at the index but at the next follow-up time, and they had a blood sugar test within the target level.

Treatment intensification was defined either as the addition of a new antidiabetic drug, a change from an OAD to an injectable antidiabetic drug, or an increase in dose of an existing antidiabetic drug, without discontinuing or reducing the dose of other antidiabetic drugs.

\section{Statistical analysis}

Data were analysed using STATA ${ }^{\oplus}$ Version 14 . Descriptive statistics were used to summarise patient demographics. We considered a nonlinear model of success of clinical inertia. The dependent variable (clinical inertia) is dichotomous and can assume two levels: 0 ("no clinical inertia") or 1 ("clinical inertia"). We obtained independent variables from the electronic medical record at the index date: age, sex, duration of T2DM, health insurance coverage, history of hypertension, dyslipidaemia, gout, baseline $\mathrm{HbA}_{1 \mathrm{c}}$, number of antidiabetic drugs used, and use of insulin. The type of doctor was recorded at the occurrence of clinical inertia or at treatment intensification. Health insurance coverage was recorded as Universal Health Care Coverage (UC), Civil Servant Medical Benefit Scheme (CSMBS), Social Health Insurance (SHI), and self-pay. Hypertension, dyslipidaemia, or gout was attributed when patients were given this diagnosis by the treating doctor and/or received drug treatment. The type of doctor was recorded as general practitioner, resident, or specialist. Externs and interns were classified as general practitioners. Fellow and staff were classified as specialists. We selected these factors based on previously published literature and our clinical experience of patients with T2DM. Significantly associated variables $(p<0.200)$ were entered into a multivariable logistic regression model to predict clinical inertia. Predictors that had a variant inflation factor (VIF) value $>2$ were excluded from the multivariable logistic regression. The final model was tested for goodness of fit by Hosmer-Lemeshow test. $P$-value less than 0.050 was used to determine the statistical significance.

\section{Results}

\section{Baseline characteristics}

Between 1 January and 31 December 2017 there were a total of 5756 T2DM outpatients.

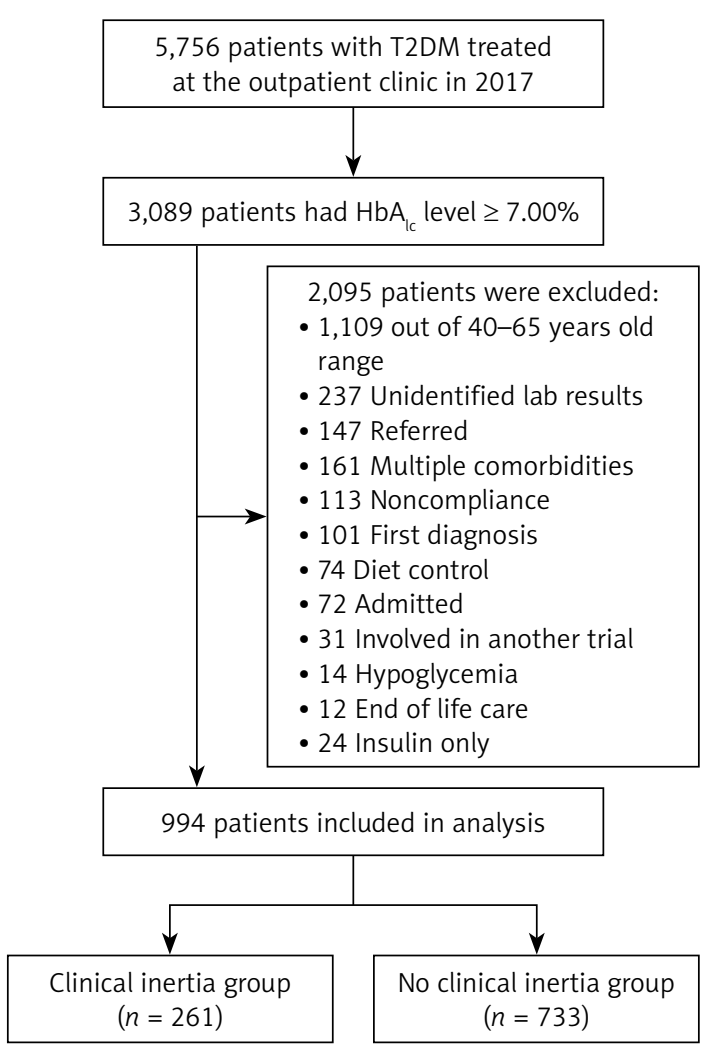

Figure 1. Flow chart: enrolment of participants

Of these, 3089 patients presenting $\mathrm{HbA}_{1 \mathrm{c}}$ level $\geq 7.00 \%$; 994 patients met the inclusion criteria, and 2095 patients met the exclusion criteria (Figure 1). A total of 994 patients were included in this study. Among all patients, 58.6\% were female, the mean age of patients was $55.55 \pm 6.10$ years, median (IQR) duration of diabetes was 5 (2-9) years, and baseline $\mathrm{HbA}_{1 \mathrm{c}}$ was mostly 7.00-7.99\%. Most participants were covered by social health insurance. In addition, most patients used two OADs and were treated mainly by specialists (Table I).

\section{Clinical inertia and associated factors}

This study found that 261 (26.2\%) T2DM outpatients experienced clinical inertia. We found four factors associated with clinical inertia: the use of insulin, $\mathrm{HbA}_{1 c}$ at the index date, the number of drugs used, and the type of doctor. Patients using insulin were associated with reduced risk of clinical inertia compared with patients not using insulin (adjusted OR (95\% Cl): 0.59 (0.36-0.97)). Patients with $\mathrm{HbA}_{1 \mathrm{c}}$ level $\geq 9.00 \%$ at the index date had significantly reduced clinical inertia compared with patients presenting $\mathrm{HbA}_{1 \mathrm{c}}$ level 7.007.99\% (adjusted OR (95\% Cl): 0.60 (0.40-0.91)). An increased number of antidiabetic drugs used at the index date was significantly associated with increased clinical inertia experience. Treatment by general practitioners was significantly associated 
Table I. Baseline characteristics

\begin{tabular}{|c|c|c|c|c|}
\hline Characteristic & $\begin{array}{c}\text { All } \\
(n=994)\end{array}$ & $\begin{array}{l}\text { Clinical inertia } \\
\quad(n=261)\end{array}$ & $\begin{array}{c}\text { No clinical } \\
\text { inertia }(n=733)\end{array}$ & $P$-value* \\
\hline \multicolumn{5}{|l|}{ Sex: } \\
\hline Female & $583(58.6)$ & $145(55.6)$ & $438(59.8)$ & 0.237 \\
\hline Male & $411(41.4)$ & $116(44.4)$ & $295(40.2)$ & \\
\hline Age [years] & $55.55 \pm 6.10$ & $55.92 \pm 6.20$ & $55.42 \pm 6.06$ & 0.250 \\
\hline Duration of T2DM [years] & $5(2-9)$ & $6(3-9)$ & $5(2-9)$ & 0.341 \\
\hline \multicolumn{5}{|l|}{ Health insurance: } \\
\hline Self-pay & $37(3.7)$ & $7(2.7)$ & $30(4.1)$ & 0.001 \\
\hline $\begin{array}{l}\text { Civil Servant Medical Benefit } \\
\text { Scheme }\end{array}$ & $411(41.4)$ & $135(51.7)$ & $276(37.6)$ & \\
\hline Social Health Insurance & $458(46.1)$ & 98 (37.6) & $360(49.1)$ & \\
\hline Universal Coverage Scheme & $88(8.8)$ & $21(8.1)$ & $67(9.1)$ & \\
\hline Current drinker & $127(13.4)$ & $33(13.6)$ & $94(13.3)$ & 0.893 \\
\hline Current smoker & $33(3.5)$ & $8(3.3)$ & $25(3.5)$ & 0.863 \\
\hline Hypertension & $726(73.0)$ & $199(76.2)$ & $527(71.9)$ & 0.174 \\
\hline Dyslipidaemia & $690(69.4)$ & $195(74.7)$ & $495(67.5)$ & 0.031 \\
\hline Gout & $25(2.5)$ & $10(3.8)$ & $15(2.0)$ & 0.114 \\
\hline \multicolumn{5}{|l|}{ Charlson comorbidity index: } \\
\hline 1 & $838(84.3)$ & $218(83.5)$ & $620(84.6)$ & 0.686 \\
\hline 2 & $156(15.7)$ & $43(16.5)$ & $113(15.4)$ & \\
\hline \multicolumn{5}{|l|}{$\mathrm{HbA}_{1 \mathrm{c}}$ at index date: } \\
\hline $7.00-7.99 \%$ & $494(49.7)$ & $149(57.1)$ & $345(47.1)$ & 0.005 \\
\hline $8.00-8.99 \%$ & $276(27.8)$ & $70(26.8)$ & $206(28.1)$ & \\
\hline$\geq 9.00 \%$ & $224(22.5)$ & $42(16.1)$ & $182(24.8)$ & \\
\hline \multicolumn{5}{|l|}{ Lipid profile: } \\
\hline Total cholesterol [mg/dl] & $170.40 \pm 43.48$ & $169.28 \pm 44.08$ & $170.86 \pm 43.29$ & 0.700 \\
\hline Triglyceride [mg/dl] & $136(96-199)$ & $152(103-218)$ & $129(95-190)$ & 0.042 \\
\hline $\mathrm{HDL}-\mathrm{C}[\mathrm{mg} / \mathrm{dl}]$ & $51.24 \pm 22.45$ & $48.98 \pm 12.61$ & $52.18 \pm 25.40$ & 0.049 \\
\hline LDL-C [mg/dl] & $96(78-126)$ & $93(80-125)$ & $97(78-128)$ & 0.626 \\
\hline \multicolumn{5}{|l|}{ Blood pressure: } \\
\hline Systolic [mm Hg] & $132.07 \pm 14.42$ & $133.17 \pm 14.53$ & $131.68 \pm 14.36$ & 0.150 \\
\hline Diastolic [mm Hg] & $77.02 \pm 10.36$ & $76.20 \pm 11.37$ & $77.31 \pm 9.97$ & 0.162 \\
\hline eGFR $\left[\mathrm{ml} / \mathrm{min} / 1.73 \mathrm{~m}^{2}\right]$ & $86.00 \pm 20.26$ & $86.56 \pm 20.27$ & $85.80 \pm 20.27$ & 0.663 \\
\hline $\mathrm{BMI}\left[\mathrm{kg} / \mathrm{m}^{2}\right]$ & $26.90 \pm 4.94$ & $27.22 \pm 4.98$ & $26.78 \pm 4.92$ & 0.276 \\
\hline Number of drugs used & $2.17 \pm 1.03$ & $2.31 \pm 1.05$ & $2.12 \pm 1.02$ & 0.011 \\
\hline The use of insulin & $154(15.5)$ & $26(10.0)$ & $128(17.5)$ & 0.004 \\
\hline \multicolumn{5}{|l|}{ Type of doctor: } \\
\hline General practitioners & $213(21.4)$ & $84(32.2)$ & $129(17.6)$ & $<0.001$ \\
\hline Residents & $350(35.2)$ & $80(30.6)$ & $270(36.8)$ & \\
\hline Specialists & 431 (43.4) & $97(37.2)$ & $334(45.6)$ & \\
\hline
\end{tabular}

Values are summarised as mean $\pm S D$ or median $(I Q R)$. Categorical variables are summarised as percentages. ${ }^{*}$-value for statistical significance was obtained using Fisher's exact test for categorical variables or independent $t$-test or Mann-Whitney $U$ test for continuous variables, as appropriate. mean $\pm S D-$ mean \pm standard deviation, median (IQR) - median (interquartile range), HbA ${ }_{1 c}-g l y c a t e d$ haemoglobin, HDL-C - high-density lipoprotein cholesterol, LDL-C - low-density lipoprotein cholesterol, eGFR - estimated glomerular filtration rate, $B M I-$ body mass index. 
Table II. Factors associated with clinical inertia among patients with T2DM

\begin{tabular}{|c|c|c|c|c|}
\hline Factor & $\begin{array}{l}\text { Crude OR } \\
(95 \% \mathrm{Cl})\end{array}$ & $P$-value* & $\begin{array}{l}\text { Adjusted OR } \\
(95 \% \mathrm{Cl})\end{array}$ & $P$-value** \\
\hline \multicolumn{5}{|l|}{ Sex: } \\
\hline Female & 1 & & & \\
\hline Male & $1.19(0.89-1.58)$ & 0.237 & & \\
\hline Age [years] & $1.01(0.99-1.04)$ & 0.250 & & \\
\hline \multicolumn{5}{|l|}{ Duration of T2DM: } \\
\hline $1-5$ years & 1 & & & \\
\hline$>5$ years & $1.14(0.86-1.51)$ & 0.369 & & \\
\hline \multicolumn{5}{|l|}{ Health insurance: } \\
\hline Self-pay & 1 & & 1 & \\
\hline Civil Servant Medical Benefit Scheme & $2.10(0.90-4.90)$ & 0.087 & $2.19(0.91-5.27)$ & 0.081 \\
\hline Social Health Insurance & $1.17(0.50-2.74)$ & 0.723 & $1.03(0.42-2.50)$ & 0.948 \\
\hline Universal Coverage Scheme & $1.34(0.52-3.50)$ & 0.546 & $1.16(0.43-3.15)$ & 0.766 \\
\hline Hypertension & $1.26(0.90-1.74)$ & 0.174 & $1.09(0.77-1.55)$ & 0.632 \\
\hline Dyslipidaemia & $1.42(1.03-1.95)$ & 0.031 & $1.37(0.97-1.92)$ & 0.073 \\
\hline Gout & $1.91(0.85-4.30)$ & 0.120 & $1.78(0.75-4.19)$ & 0.190 \\
\hline \multicolumn{5}{|l|}{$\mathrm{HbA}_{1 \mathrm{c}}$ at index date: } \\
\hline $7.00-7.99 \%$ & 1 & & 1 & \\
\hline $8.00-8.99 \%$ & $0.79(0.56-1.10)$ & 0.157 & $0.84(0.60-1.20)$ & 0.343 \\
\hline$\geq 9.00 \%$ & $0.53(0.36-0.79)$ & 0.001 & $0.60(0.40-0.91)$ & 0.016 \\
\hline \multicolumn{5}{|l|}{ Number of drugs used: } \\
\hline 1 & 1 & & 1 & \\
\hline 2 & $1.31(0.91-1.88)$ & 0.146 & $1.68(1.15-2.47)$ & 0.008 \\
\hline 3 & $1.74(1.18-2.59)$ & 0.006 & $2.14(1.41-3.27)$ & $<0.001$ \\
\hline$\geq 4$ & $1.54(0.92-2.58)$ & 0.099 & $2.00(1.12-3.55)$ & 0.018 \\
\hline The use of insulin & $0.52(0.33-0.82)$ & 0.005 & $0.59(0.36-0.97)$ & 0.036 \\
\hline \multicolumn{5}{|l|}{ Type of doctor: } \\
\hline General practitioner & 1 & & 1 & \\
\hline Resident & $0.46(0.31-0.66)$ & $<0.001$ & $0.42(0.28-0.62)$ & $<0.001$ \\
\hline Specialist & $0.45(0.31-0.64)$ & $<0.001$ & $0.35(0.23-0.52)$ & $<0.001$ \\
\hline
\end{tabular}

${ }^{*} P$-value for statistical significance was obtained using univariable logistic regression. " $P$-value for statistical significance was obtained using multivariable logistic regression.

with a longer delay of treatment intensification compared with management by specialists (adjusted OR (95\% Cl): $0.35(0.23-0.52))$ (Table II).

\section{Discussion}

This study showed that in real-world clinical practice in a tertiary teaching hospital in Thailand, the clinical inertia among patients with T2DM aged $40-65$ years was $26.2 \%$. This occurrence was quite low compared with related studies [2, 9-11, 14, 18-20]. One possible explanation for this was our patient selection criteria. Our study included T2DM patients who were young and exhibited less comorbidity. The mean age was 55.55 \pm 6.10 years. The Charlson's comorbidity index score of most participants was 1 point. Clinical inertia was more frequently observed among older patients [5]. Patients at older age are more prone to hypoglycaemia than younger patients, so phy- 
sicians tend to increase treatment intensification in a younger age group. In addition, this study selected patients with fewer comorbidities. Patients with more comorbidities tend to use many drugs. Treatment intensification cases should be aware of drug-drug interactions. Therefore, patients with less comorbidity tend to intensify. As a result, patients at younger age and with fewer comorbidities generally receive appropriate treatment intensification [21]. Additionally, there are many specialists in the hospital to educate patients on diabetes. This could be the cause of low occurrence. Furthermore, differences in clinical inertia assessment, including threshold to assess clinical inertia and definition of treatment intensification, may have affected the occurence. First, our study assessed clinical inertia at the index date and subsequent prescription, unlike other studies, which assessed clinical inertia within the timeframe. Second, treatment intensification was defined as any OADs and injectable antidiabetic drugs in our study. Other studies defined it as injectable antidiabetic drugs only [10, 22].

Regarding conducting a study in a tertiary teaching hospital in Thailand, the frequency of clinical inertia in our study was lower than the former study [10]. The different outcomes among these two studies may have been due to the selection of research participants included in the studies and the definition of treatment intensification. Moreover, the former study showed that $38.8 \%, 46.9 \%$, and $14.3 \%$ of the patients were treated by general practitioners, internal medicines practitioners, and endocrinologists, respectively [10]. In our study, patients were treated by general practitioners, residents, and specialists, totalling $21.4 \%, 35.2 \%$, and $43.4 \%$, respectively. Patients in our study were mostly treated by specialists, unlike in the former study. Treatment by specialists might have made clinical inertia occur less frequently [23].

\section{Factors associated with clinical inertia}

Our study found that use of insulin, $\mathrm{HbA}_{1 \mathrm{c}}$ at the index date, number of drugs used, and type of doctor were factors significantly associated with clinical inertia. These factors were similar to related studies.

\section{The use of insulin}

Our study revealed that patients with T2DM using insulin had a decreased chance of experiencing clinical inertia. Patients using insulin were more progressive in their disease than patients not using insulin [22]. Another reason was the lack of an upper limit regarding insulin doses [24]. Therefore, physicians tend to intensify treatment to decrease the occurrence of complications.

\section{$\mathrm{HbA}_{1 \mathrm{c}}$ at the index date}

Patients with a higher $\mathrm{HbA}_{1 \mathrm{c}}$ at the index date had significantly less clinical inertia. Related studies showed that patients having $\mathrm{HbA}_{1 \mathrm{c}}$ level 8.0$9.0 \%$, and $\geq 9.0 \%$ had a significantly shorter time to reach treatment intensification than patients with an $\mathrm{HbA}_{1 c}$ level 7.0-8.0\% [25]. This result was consistent with Lin et al., who showed that a higher index $\mathrm{HbA}_{1 \mathrm{c}}$ significantly reduced the occurrence of clinical inertia $(p<0.001)$ [9]. Patients with $\mathrm{HbA}_{1 \mathrm{c}}$ level $\geq 8.0 \%$ had 5.52 times greater risk of intensification than patients with $\mathrm{HbA}_{1 \mathrm{c}}$ level $<6.5 \%$ $(p<0.001)$ [26]. Evidence from a large real-world dataset revealed that patients who had $\mathrm{HbA}_{1 \mathrm{c}}$ level $\geq 9.0 \%, 8.0-8.9 \%$, and $7.0-7.9 \%$ received treatment intensification of $59.6 \%, 46.7 \%$, and $28.4 \%$, respectively [4]. One possible explanation is that physicians may be less inclined to intensify therapy among patients having an $\mathrm{HbA}_{1 \mathrm{c}}$ level near the target $[2,25]$. They possibly recommend lifestyle modification instead $[19,20]$. Patients having an extremely high $\mathrm{HbA}_{1 \mathrm{c}}$ level above target often experience treatment intensification because controlling the glucose level within the target is beneficial in reducing complications [27-30].

\section{Number of drugs used}

In our study, an increase in the number of drugs used at the index date was associated with experiencing clinical inertia. However, the association between the number of drugs used and clinical inertia in T2DM remains ambiguous, in contrast with other studies. Lin et al. found that an increase in the number of drugs used significantly increased the prevalence of clinical inertia $(p<0.001)$ [9], similarly to our study. Ruiz Negron et al. found that clinical inertia was associated with a higher number of baseline antidiabetic drugs [19]. In contrast, the results of the study by Osataphan et al. showed that patients receiving more than two OADs had 1.4 times greater insulin initiation than patients receiving two OADs $(p=0.51)$ [10]. Khunti et al. found that patients using a higher number of OADs received significantly more treatment intensification with insulin than patients with a lower number of OADs ( $p=0.0012)$ [22]. Patients using a higher number of drugs were more prone to clinical inertia because adding more antidiabetics is probably less desirable for patients already using a high number of drugs. Additionally, treatment intensification increased drug-drug interactions, medication-related adverse events, and polypharmacy $[19,21]$.

\section{Type of doctor}

The type of treating doctor was also found to be associated with clinical inertia. Our study 
found that treatment by a specialist was less likely to result in clinical inertia than treatment by a general practitioner $(p<0.001)$. The Osataphan et al. study also found that treatment by general practitioners was 2.95 times more likely to result in clinical inertia than treatment by specialists [10]. The study by Shah et al. also found that specialists' care (45.1\%) was more intensive than general practitioners' care $(37.4 \%)(p=0.009)$ [23]. Patients treated by general practitioners experienced more clinical inertia because general practitioners have less experience in treatment than specialists and are less certain about optimal drug choices [9]. Given this finding, a need was observed for general practitioners to undertake confirming professional education to manage patients with T2DM.

\section{Other factors}

Aside from significantly associated factors, health insurance plans were revealed as an interesting factor. This study found that a difference in health insurance was not associated with clinical inertia, similarly to the study by Osataphan et al. [10]. This result revealed that health insurance plans did not have an impact on T2DM treatment in Thailand because all health insurance plans cover an essential drug (ED). Antidiabetic drugs in the essential drug are optimal and sufficient for treating diabetes, and basic laboratory tests and treatment by specialists are covered by all health insurance plans.

\section{Limitations}

This study encountered limitations. First, this study employed a retrospective observational design. We were concerned about missing data, including adherence and lifestyle modifications. Second, we also did not know the reasons why doctors did not add new drugs or increased the dose of existing drugs because this was not recorded in the OPD cards. Third, we were unable to collect analysis data concerning the patient's socio-economic and education level, occupation, and level of patient diabetes knowledge, to determine whether these variables influenced clinical inertia. Fourth, this study was conducted in a tertiary care hospital. Different factors regarding lower level hospitals and the community setting would be involved such as availability of drugs, knowledge of doctors, etc. While these results make a valuable contribution, they should be interpreted with caution.

In conclusion, the clinical inertia in this study was about $26 \%$. The finding of this study revealed that the use of insulin, $\mathrm{HbA}_{1 \mathrm{c}}$ at the index date, number of drugs used, and type of doctor were associated with clinical inertia. A better understanding of clinical inertia and the specific related interventions should be developed to more precisely address this problem.

\section{Acknowledgments}

The research work was conducted at Chiang Mai University. We gratefully thank the Graduate School; the income budget 2018 Faculty of Pharmacy, Chiang Mai University for financial support.

\section{Conflict of interest}

The authors declare no conflict of interest.

\section{References}

1. O'Connor PJ, Sperl-Hillen JAM, Johnson PE, Rush WA, Biltz G. Advances in patient safety clinical inertia and outpatient medical errors. In: Advances in Patient Safety: From Research to Implementation (Volume 2: Concepts and Methodology). Henriksen K, Battles JB, Marks ES, Lewin DI (eds). Rockville (MD): Agency for Healthcare Research and Quality (US) 2005.

2. Mahabaleshwarkar R, Gohs F, Mulder H, et al. Patient and provider factors affecting clinical inertia in patients with type 2 diabetes on metformin monotherapy. Clin Ther 2017; 39: 1658-70.e6.

3. Bailey CJ. Under-treatment of type 2 diabetes: causes and outcomes of clinical inertia. Int J Clin Pract 2016; 70: 988-95.

4. Pantalone KM, Misra-Hebert AD, Hobbs TM, et al. Clinical inertia in type 2 diabetes management: evidence from a large, real-world data set. Diabetes Care 2018; 41: e113-e4.

5. Reach G, Pechtner V, Gentilella R, Corcos A, Ceriello A. Clinical inertia and its impact on treatment intensification in people with type 2 diabetes mellitus. Diabetes Metab 2017; 43: 501-11.

6. Ma CC, Duan CC, Huang RC, Tang HQ. Association of circulating cystatin $\mathrm{C}$ levels with type 2 diabetes mellitus: a systematic review and meta-analysis. Arch Med Sci 2019; 16: 648-56.

7. Haberka M, Jankowski P, Kosior D, et al. Treatment goal attainment for secondary prevention in coronary patients with or without diabetes mellitus - Polish multicenter study POLASPIRE. Arch Med Sci 2020. DOI: https://doi.org/10.5114/aoms.2020.92558.

8. Giugliano D, Maiorino MI, Bellastella G, Esposito K. Clinical inertia, reverse clinical inertia, and medication non-adherence in type 2 diabetes. J Endocrinol Invest 2019; 42: 495-503.

9. Lin J, Zhou S, Wei W, Pan C, Lingohr-Smith M, Levin P. Does clinical inertia vary by personalized a1c goal? A study of predictors and prevalence of clinical inertia in a U.S. Managed-care setting. Endocr Pract 2016; 22: 151-61.

10. Osataphan S, Chalermchai T, Ngaosuwan K. Clinical inertia causing new or progression of diabetic retinopathy in type 2 diabetes: a retrospective cohort study. J Diabetes 2017; 9: 267-74.

11. Pholdee L, Vejakama P, Khunawaradisai N, Watcharathanakij S. Clinical inertia in type 2 diabetic patients in community hospitals in Ubon Ratchathani. Thai J Pharm Pract 2020; 12: 128-39. 
12. Paul SK, Klein K, Thorsted BL, Wolden ML, Khunti K. Delay in treatment intensification increases the risks of cardiovascular events in patients with type 2 diabetes. Cardiovasc Diabetol 2015; 14: 100.

13. Khunti K, Gomes MB, Pocock S, et al. Therapeutic inertia in the treatment of hyperglycaemia in patients with type 2 diabetes: a systematic review. Diabetes Obes Metab 2018; 20: 427-37.

14. Alvarenga MA, Komatsu WR, de Sa JR, Chacra AR, Dib SA. Clinical inertia on insulin treatment intensification in type 2 diabetes mellitus patients of a tertiary public diabetes center with limited pharmacologic armamentarium from an upper-middle income country. Diabetol Metab Syndr 2018; 10: 77.

15. Khunti S, Khunti K, Seidu S. Therapeutic inertia in type 2 diabetes: prevalence, causes, consequences and methods to overcome inertia. Ther Adv Endocrinol Metab 2019; 10: 2042018819844694.

16. Medical records and statistics [Internet]. 2015 [cited 16 October 2019]. Available from: https://w2.med.cmu. ac.th/medrec/medrec/PAGE.html.

17. Charlson ME, Pompei P, Ales KL, MacKenzie CR. A new method of classifying prognostic comorbidity in longitudinal studies: development and validation. J Chronic Dis 1987; 40: 373-83.

18. Machado-Duque ME, Ramirez-Riveros AC, Machado-Alba JE. Effectiveness and clinical inertia in patients with antidiabetic therapy. Int J Clin Pract 2017; 71: doi: 10.1111/ijcp.12954.

19. Ruiz-Negron N, Wander C, McAdam-Marx C, Pesa J, Bailey RA, Bellows BK. Factors associated with diabetes-related clinical inertia in a managed care population and its effect on hemoglobin a1c goal attainment: a claimsbased analysis. J Manag Care Spec Pharm 2019; 25: 304-13.

20. Mata-Cases M, Franch-Nadal J, Real J, et al. Therapeutic inertia in patients treated with two or more antidiabetics in primary care: factors predicting intensification of treatment. Diabetes Obes Metab 2018; 20: 103-12.

21. Fu AZ, Sheehan JJ. Treatment intensification for patients with type 2 diabetes and poor glycaemic control. Diabetes Obes Metab 2016; 18: 892-8.

22. Khunti K, Nikolajsen A, Thorsted BL, Andersen M, Davies MJ, Paul SK. Clinical inertia with regard to intensifying therapy in people with type 2 diabetes treated with basal insulin. Diabetes Obes Metab 2016; 18: 401-9.

23. Shah BR, Hux JE, Laupacis A, Zinman B, van Walraven C. Clinical inertia in response to inadequate glycemic control: do specialists differ from primary care physicians? Diabetes Care 2005; 28: 600-6.

24. Harris SB, Kapor J, Lank CN, Willan AR, Houston T. Clinical inertia in patients with T2DM requiring insulin in family practice. Can Fam Physician 2010; 56: e418-24.

25. Fu AZ, Qiu Y, Davies MJ, Radican L, Engel SS. Treatment intensification in patients with type 2 diabetes who failed metformin monotherapy. Diabetes Obes Metab 2011; 13: 765-9.

26. Raebel MA, Ellis JL, Schroeder EB, et al. Intensification of antihyperglycemic therapy among patients with incident diabetes: a Surveillance Prevention and Management of Diabetes Mellitus (SUPREME-DM) study. Pharmacoepidemiol Drug Saf 2014; 23: 699-710.

27. The VADT Investigators. Glucose control and vascular complications in veterans with type 2 diabetes. N Engl J Med 2009; 360: 129-39.
28. The ADVANCE Collaborative Group. Intensive blood glucose control and vascular outcomes in patients with type 2 diabetes. N Engl J Med 2008; 358: 2560-72.

29. The Action to Control Cardiovascular Risk in Diabetes Study Group. Effects of intensive glucose lowering in type 2 diabetes. N Engl J Med 2008; 358: 2545-59.

30. Shek AB, Alieva RB, Kurbanov RD, Hoshimov SU, Nizamov UI, Ziyaeva AV. Can metformin stabilize PCSK9 leve in stable coronary artery disease patients treated with statins? Arch Med Sci Atheroscler Dis 2019; 4: e144-50. 